\title{
Educational Value of a 3D Printer in Ophthalmology Training
}

\author{
Jawad Arshad, BA ${ }^{1, *}$ Richard W. Helms, PhD ${ }^{1, *}$ Faruk H. Orge, MD ${ }^{1}$ Rony R. Sayegh, MD ${ }^{1}$ \\ ${ }^{1}$ Department of Ophthalmology, University Hospitals Eye Institute, Case \\ Western Reserve University School of Medicine, Cleveland, Ohio \\ Address for correspondence Rony R. Sayegh, MD, Department of \\ Ophthalmology, University Hospitals Eye Institute, 11100 Euclid \\ Avenue, Cleveland, OH 44106 (e-mail: rrs109@case.edu).
} Journal of Academic Ophthalmology 2018;10:e69-e71.

\begin{abstract}
Three-dimensional (3D) printers are increasingly being used in medicine for surgical planning, medical education, patient education, research, and device development. We explore the educational value of a 3D printer for trainees in an ophthalmology residency program. A 3D printer was made available to medical students, residents, and clinical and

Keywords

- 3D printing

- residency

- education

- ophthalmology

- slit-lamp

- cellphone

- ultrasound biomicroscopy research fellows in the Department of Ophthalmology at Case Western Reserve University. One of the medical students was proficient in the technology and was available to help. Multiple projects were initiated including the manufacturing of slit-lamp cellphone adapters and various interface and integral custom-made parts for research applications. The 3D printer was found to be useful by 20 of 21 trainees surveyed with 17 of 20 saying they would use it after graduation if they had access to one. All the respondents felt that the availability of the technology can contribute to increased innovation in the ophthalmology department. We encourage other ophthalmology departments to experiment with $3 \mathrm{D}$ printing as a tool to foster innovation and creativity for trainees.
\end{abstract}

Three-dimensional (3D) printers are increasingly being used in medicine for surgical planning, medical education, patient education, research, and device development. Ophthalmology is a field that relies heavily on direct visualization of ocular structures and is rich in instrumentation, making 3D printing potentially very useful. ${ }^{1}$ 3D printers and the plastic filament (printing material) have become increasingly affordable. Software for driving the printer and designing 3D models has also become more user-friendly. Therefore, it has become feasible to provide trainees with access to a 3D printer for education and experimentation. Here, we describe some of the innovative uses of this technology that were performed by trainees in an ophthalmology residency program.

\section{Methods}

A MakerGear M2 3D printer (MakerGear, Beachwood, OH) was connected to a dedicated computer which was made

\footnotetext{
Authors Jawad Arshad and Richard W. Helms contributed equally
} to this work.

received

November 19, 2017

accepted after revision

April 9, 2018 available to medical students, residents, as well as clinical and research fellows in the Department of Ophthalmology. It was placed in a common area of the department offices that is only accessible to ophthalmology staff and where trainees frequently take their breaks. The availability of the 3D printer was communicated to individual trainees and during ophthalmology grand rounds to the entire department. One medical student who was familiar with the technology helped trainees assess the feasibility of their ideas and transmitted his knowledge to them. Sources of training such as online videos and Web sites were also used.

\section{Results}

Project ideas originated from trainees with help from the faculty, and were based on a need for certain items in the department or a gap that was identified by the trainees and students. Having the physical 3D-printed item available for use drew more individuals to suggest improvements in design and come up with other novel ideas.

Copyright $\odot 2018$ by Thieme Medical Publishers, Inc., 333 Seventh Avenue, New York, NY 10001, USA. Tel: +1(212) 584-4662.
License terms

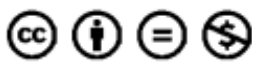

DOI https://doi.org/

10.1055/s-0038-1653973. ISSN 2475-4757. 


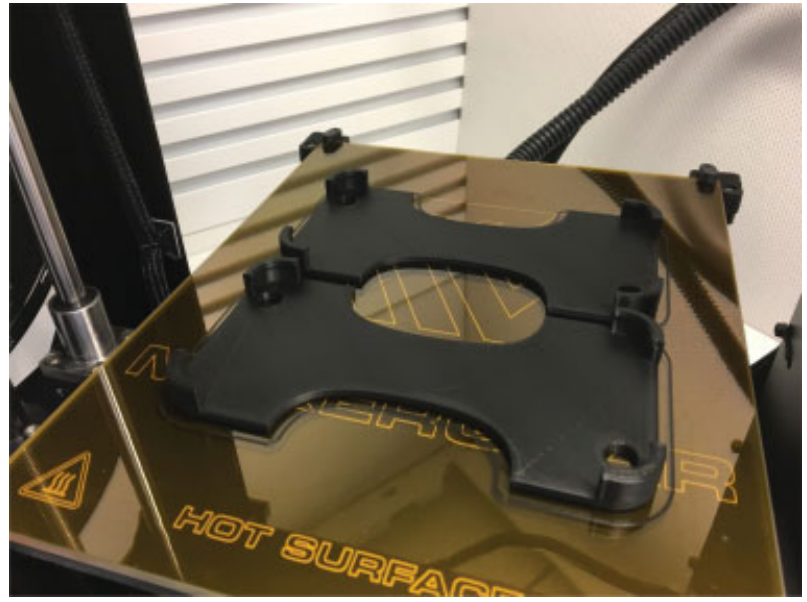

Fig. 1 Printing of slit-lamp cellphone adapters.

One such project involved the manufacturing of slit-lamp cellphone adapters ( - Fig. 1) customized for various slitlamps and cellphones by measuring the dimensions of the slit-lamp oculars and the myriad cellphones owned by trainees. ${ }^{2}$ This idea stemmed from the need for after-hours photography in the clinic and the limited compatibility of the commercially available adapters to an ever increasing number of phone manufacturers and models. These 3D-printed custom adapters were used by residents for documentation of ocular findings in the clinic and in the emergency department while on call, and provided photographs for consultation with the on-call faculty and for regularly scheduled educational case presentations. They were also used to document and teach various eye pathology and to demonstrate the use of the slit-lamp to medical students during their ophthalmology rotation. Adapters were also made to fit the surgical microscopes to obtain still images and video clips during various ophthalmic procedures. Further modification on a previously described design ${ }^{3}$ led to the manufacturing of a customized cellphone attachment for indirect ophthalmoscopy for documenting posterior pole structures and related pathology.

A particularly innovative application was the manufactur-

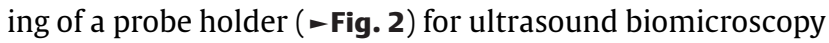
(UBM). ${ }^{4}$ The UBM probe was attached to a precision translation stage which allowed coordination of the movement of the probe with the image acquisition (-Fig. 2). This allowed precise image acquisition that led to high-resolution 3D anterior segment imaging. Through this technology, structures were visualized in great detail and volumetric measurement of these structures was possible.

The 3D printer has also been a great resource for our department's basic science faculty. A custom experimental apparatus can often be 3D printed at a fraction of the cost of traditional sources. The custom build apparats were easy to modify depending on the need, and efficiently printed which helped tremendously on research turn around. Our 3D printer has been used to help create a vertical tube rack and corneal flanges for porcine outflow experiments, an

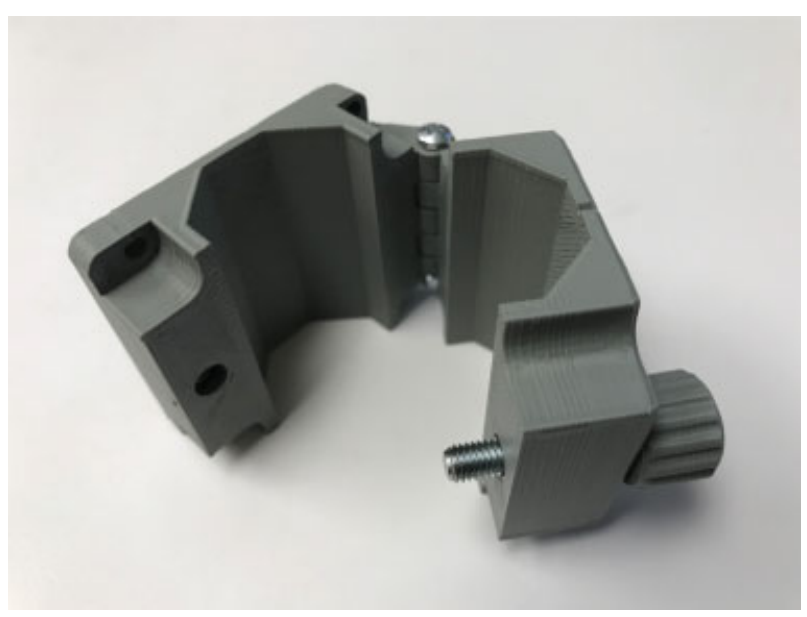

Fig. 2 Ultrasound biomicroscopy probe holder.

OCT-mounted lens holder for an accommodation study (-Fig. 3), a table-top globe holder for ex vivo imaging (-Fig. 4), and many other tools.

Each of these projects reached completion and was presented by the involved trainees at national meetings.

A total of 23 trainees were surveyed: 18 residents, 3 fellows, and 2 medical students. Twenty-one complete or partial responses to the survey questions were received. The 3D printer was found to be useful by 20 of 21 trainees who responded. Seventeen of the 20 respondents indicated that they would use 3D printing after their graduation if they have access to one. All 19 of the 19 respondents felt that the availability of the technology can contribute to increased innovation in the ophthalmology department.

Nine out of 16 respondents expressed interest in formal training in both designing and 3D printing, 3 were interested only in learning how to download and print 3D models from online repositories, 2 preferred focusing on ideas and delegating the design and manufacturing to the experienced user, and 2 felt that they had no further use for the technology.

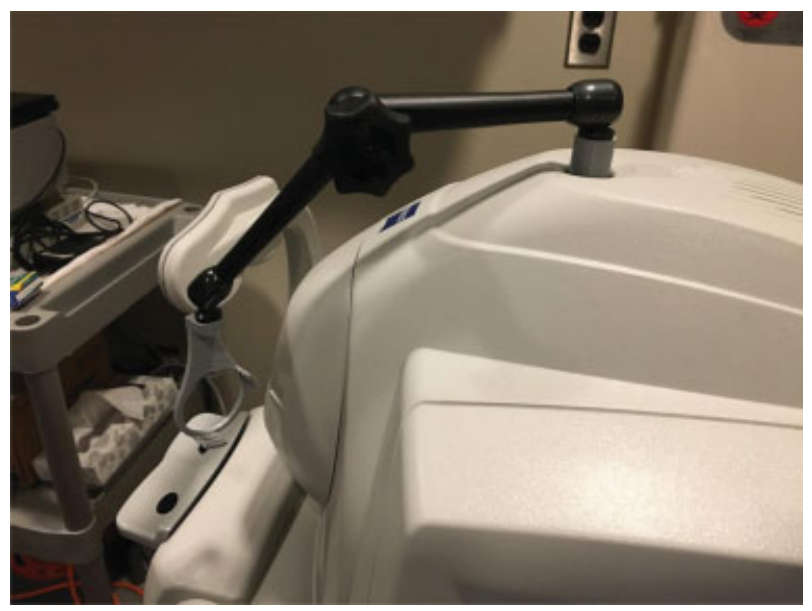

Fig. 3 OCT-mounted lens holder for an accommodation study. 


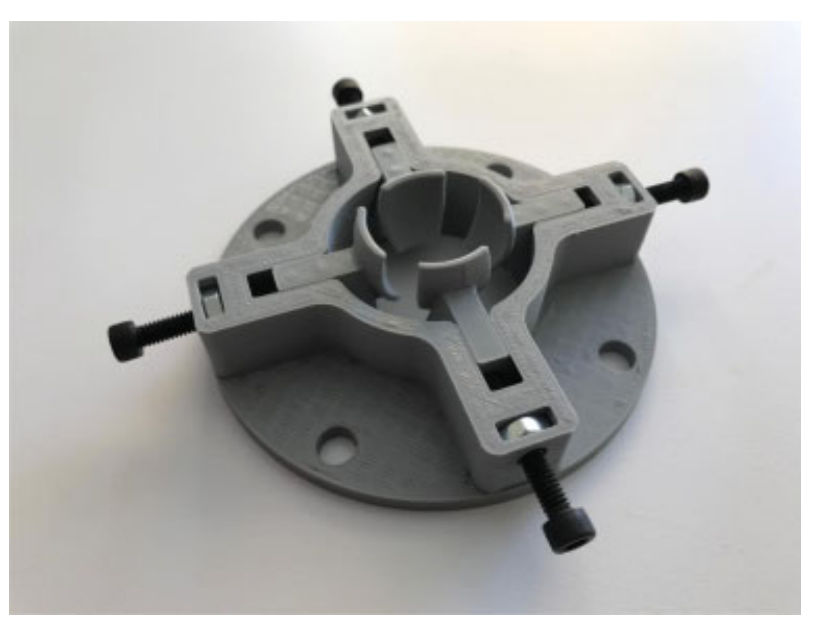

Fig. 4 Table-top globe holder for ex vivo imaging.

\section{Discussion}

There have been multiple reports on the use of 3D printers in ophthalmology. Some educational uses include the reproduction of sections of the human orbit for the study of anatomy ${ }^{5}$ and the printing of 3D orbits for surgical training. ${ }^{6}$ 3D printing was also used in surgical planning for orbital fracture repair ${ }^{7}$ and in stereotactic surgery for uveal melanomas. ${ }^{8}$ Other uses include the manufacturing of ocular prostheses ${ }^{9}$ as well as various surgical instruments. ${ }^{10}$ This is the first report in which a 3D printer was not only used for the creation of surgical and educational tools but was used in itself as a tool to foster innovation and creativity in an academic ophthalmic educational program.

What we have learned could be important for the future success of integrating 3D printers into medical education programs. In similar settings, an individual who is well versed in the usage of the 3D printing technology is necessary with a willingness to transmit the knowledge to other users. Reminding the coworkers and students on how the 3D printer could be utilized by demonstrating examples as well as allowing easy access to the machine, designs, material, and expertise appears to help increase the use of the technology. The prospect of improving the documentation of pathology, improving the research and in turn allowing to be able to present at local and national meetings, encouraged the usage of the 3D printer. The high demand was also fostered via a competition for the most innovative and useful 3D-related project.

Much has been learned about the projects themselves as well, and about what makes them successful. For example, despite wide adoption originally, the cumbersome design of the cellphone adapters made them difficult to carry around at all times. This has been addressed by placing several of these adapters in an accessible location in the emergency department next to the slit-lamp that is used by the on-call residents and emergency room staff. By having the 3Dprinted device attached to a commonly used piece of equipment such as the OCT, UBM, or slit-lamp, it becomes natural extension of the apparatus, increasing its usefulness. Ideas on miniaturization of the design of the slit-lamp adaptors are currently being worked on as well.

We encourage ophthalmology training programs to consider providing access to 3D printing to their trainees, both to maximize learning engagement and creativity and to help with efficiency in patient care. The technology proved to provide cost-saving measures due to its efficacy in creating working solutions in the clinical and research arena. As in many learning institutions (engineering, architecture, design, etc.), we see the strong possibility of the 3D printing becoming part of the medical curriculum where students will be encouraged to take on projects which would lead to a product with novel medical applications in their respective fields of interest.

\section{Funding}

None.

\section{Conflict of Interest}

None declared.

\section{References}

1 Huang W, Zhang X. 3D Printing: print the future of ophthalmology. Invest Ophthalmol Vis Sci 2014;55(08):5380-5381

2 Boente C, Tu E, Sayegh RR. Slitlamp-mounted smartphone adapters using reverse engineering with 3D scanning and 3D printing. Invest Ophthalmol Vis Sci 2015;56(07):4103 (Abstract)

3 Haddock LJ, Kim DY, Mukai S. Simple, inexpensive technique for high-quality smartphone fundus photography in human and animal eyes. J Ophthalmol 2013;2013:518479

4 Helms R, Orge F. Volumetric measurement of anterior segment lesions using 3D reconstruction of 2D ophthalmic ultrasound images. Presented at: ARVO Imaging Conference; Seattle, WA; 2016

5 Adams JW, Paxton L, Dawes K, Burlak K, Quayle M, McMenamin PG. 3D printed reproductions of orbital dissections: a novel mode of visualising anatomy for trainees in ophthalmology or optometry. Br J Ophthalmol 2015;99(09):1162-1167

6 Scawn RL, Foster A, Lee BW, Kikkawa DO, Korn BS. Customised 3D printing: an innovative training tool for the next generation of orbital surgeons. Orbit 2015;34(04):216-219

7 Fan B, Chen H, Sun YJ, et al. Clinical effects of 3-D printing-assisted personalized reconstructive surgery for blowout orbital fractures. Graefes Arch Clin Exp Ophthalmol 2017;255(10):2051-2057

8 Furdová A, Sramka M, Thurzo A, Furdová A. Early experiences of planning stereotactic radiosurgery using 3D printed models of eyes with uveal melanomas. Clin Ophthalmol 2017;11:267-271

9 Ruiters S, Sun Y, de Jong S, Politis C, Mombaerts I. Computer-aided design and three-dimensional printing in the manufacturing of an ocular prosthesis. Br J Ophthalmol 2016;100(07):879-881

10 Ruzza A, Parekh M, Ferrari S, et al. Preloaded donor corneal lenticules in a new validated 3D printed smart storage glide for Descemet stripping automated endothelial keratoplasty. $\mathrm{Br} \mathrm{J}$ Ophthalmol 2015;99(10):1388-1395 